\title{
Factors influencing mass drug administration adherence and community drug distributor opportunity costs in Liberia: a mixed-methods approach
}

\author{
Efundem Agboraw ${ }^{1 *}$, Fred Sosu², Laura Dean ${ }^{3}$, Alice Siakeh², Rachael Thomson ${ }^{4}$, Karsor Kollie $^{5}$ and Eve Worrall ${ }^{1}$
}

\begin{abstract}
Background: Preventive chemotherapy delivered via mass drug administration (MDA) is essential for the control of neglected tropical diseases (NTDs), including lymphatic filariasis (LF), schistosomiasis and onchocerciasis. Successful MDA relies heavily on community drug distributor (CDD) volunteers as the interface between households and the health system. This study sought to document and analyse demand-side (households) and supply-side (health system) factors that affect MDA delivery in Liberia.

Methods: Working in two purposively selected counties, we conducted a household MDA access and adherence survey; a CDD survey to obtain information on direct and opportunity costs associated with MDA work; an observational survey of CDDs; and key informant surveys (KIS) with community-level health workers. Data from the CDD survey and Liberian minimum wage rates were used to calculate the opportunity cost of CDD participation per MDA round. The observational data were used to calculate the time spent on individual household-level tasks and CDD time costs per house visited. KIS data on the organisation and management of the MDA in the communities, and researcher reflections of open-ended survey responses were thematically analysed to identify key demand-and supply-side challenges.
\end{abstract}

Results: More respondents were aware of MDA than NTD in both counties. In Bong, 39\% (103/261) of respondents reported taking the MDA tablet in the last round, with "not being informed" as the most important reason for nonadherence. In Maryland, 56\% (147/263) reported taking MDA with "being absent" at the time of distribution being important for non-adherence. The mean cost per CDD of participating in the MDA round was $-\$ 11.90$ (median $\$ 5.04$, range $-\$ 169.62$ to $\$ 30.00$ ), and the mean time per household visited was 17.14 min which equates to a mean opportunity cost of $\$ 0.03$ to $\$ 0.05$ per household visited. Thematic analysis identified challenges, including shortages of and delays in medicine availability; CDD frustration over costs; reporting challenges; and household concerns about drug side effects.

Conclusions: Improved adherence to MDA and subsequent elimination of NTDs in Liberia would be supported by an improved medicine supply chain, financial compensation for CDDs, improved training, healthcare workforce strengthening, greater community involvement, capacity building, and community awareness.

*Correspondence: efundem.agboraw@lstmed.ac.uk

${ }^{1}$ Department of Vector Biology, Liverpool School of Tropical Medicine,

Pembroke Street, Liverpool L3 5 QA, UK

Full list of author information is available at the end of the article

(c) The Author(s) 2021. Open Access This article is licensed under a Creative Commons Attribution 4.0 International License, which permits use, sharing, adaptation, distribution and reproduction in any medium or format, as long as you give appropriate credit to the original author(s) and the source, provide a link to the Creative Commons licence, and indicate if changes were made. The images or other third party material in this article are included in the article's Creative Commons licence, unless indicated otherwise in a credit line to the material. If material is not included in the article's Creative Commons licence and your intended use is not permitted by statutory regulation or exceeds the permitted use, you will need to obtain permission directly from the copyright holder. To view a copy of this licence, visit http://creativecommons.org/licenses/by/4.0/. The Creative Commons Public Domain Dedication waiver (http://creativeco mmons.org/publicdomain/zero/1.0/) applies to the data made available in this article, unless otherwise stated in a credit line to the data. 
Keywords: Neglected diseases, MDA, Adherence, Opportunity cost, CDD, Community, Liberia Graphical Abstract

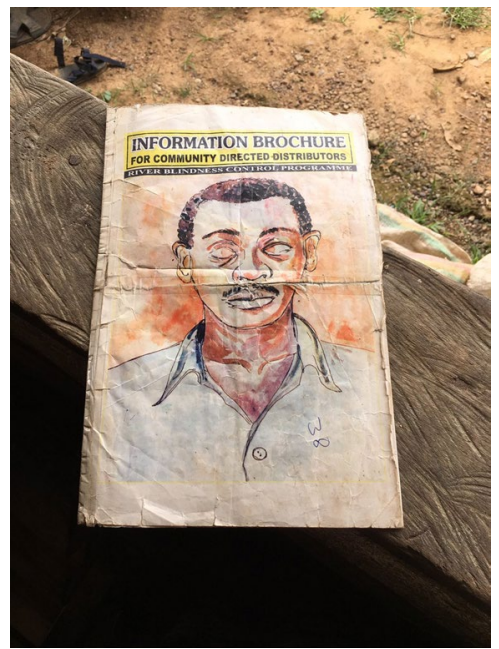

\section{Background}

Neglected tropical diseases (NTDs) are a group of 20 diseases that have historically received scant attention and are concentrated among individuals with very low incomes $[1,2]$. Preventive chemotherapy delivered via mass drug administration (MDA) is essential for the control of NTDs including lymphatic filariasis (LF), schistosomiasis and onchocerciasis [2]. Low and/or inequitable MDA coverage challenges NTD program effectiveness, the achievement of the new 2030 NTD elimination targets [3-5], and the overarching goal of universal health coverage [6]. Heavy reliance on drug donations and volunteers such as community drug distributors (CDDs) threatens MDA sustainability $[1,3]$.

Liberia is situated on the west coast of Africa bordered by Sierra Leone, Guinea, Cote d'Ivoire and the Atlantic Ocean, with a population of 5.05 million people. Onchocerciasis, LF and schistosomiasis are endemic throughout Liberia and are the most common infections among its poorest communities [7, 8]. Guided by their NTD Master Plan, the Liberian Ministry of Health and partners sought to eliminate LF, onchocerciasis and schistosomiasis by $2020[9,10]$ through a combination of annual MDA with ivermectin (IVM) and albendazole (ABD); disability management and inclusion; and vector control [7].

The national NTD program led its first 3 yearly MDA campaigns with IVM and ABD in 2012-2013 achieving $82 \%$ coverage [11]. Household acceptability and adherence to MDA and the volunteering efforts of CDDs made this possible. CDDs have been at the forefront of drug (and bed net) distribution since 2012, with some individual CDDs having over 10 years of experience. The Ebola virus disease (EVD) outbreak in Liberia (2014-2015) severely disrupted public health programs for NTDs including MDA [12]. Following containment of the EVD outbreak in 2015, the Liberian Ministry of Health and partners restarted MDA in 2017 [12].

CDDs are considered the primary care providers at the community level. However, health system and programrelated factors such as inadequate training and supervision of CDDs by health facility staff have an adverse impact on CDD performance [9, 10]. CDDs also incur direct (financial expenditure) and opportunity costs (indirect costs) for their participation in MDA programs. Opportunity cost is defined as the cost of the next-best opportunity foregone, and in the case of CDDs, this is time that could otherwise be spent on paid work or unpaid activities such as caring or food production (subsistence agriculture). In Liberia, CDDs' financial compensation is dependent on the availability of funds $[9,10]$, and hence direct and opportunity costs incurred may not be covered, presenting a barrier to their participation in MDA.

This paper presents an analysis of accessibility and adherence to MDA in the post-EVD context from the household, CDD and health system perspective in Liberia. Its findings will help support the Liberian government and partners to move towards equitable attainment of NTD elimination goals and will be of interest to policymakers and implementers facing similar challenges and wishing to develop resilient health systems [8].

The study objective was to document and analyse factors that affect accessibility and adherence to MDA on the demand-side (households) and supply-side (health 
system) in Liberia. Specific aims were to (i) determine household accessibility and adherence to MDA; (ii) document and quantify the direct and opportunity costs of CDD participation in MDA; and (iii) describe resources used in conducting MDA programs at the community level, and identify demand- and supply-side challenges that adversely affect MDA delivery.

\section{Methods}

\section{Study components}

We addressed the study aims through the following four components: household survey on MDA accessibility and adherence (HHS) (aim 1); CDD costs survey (CDD CS) (aim 2); CDD observational (time and motion) survey during household MDA delivery (CDD TM) (aim 2); key informant surveys with health workers, community health workers and community leaders to explore community-level resources needed for MDA delivery (KIS) and a qualitative synthesis of findings (Aim 3).

\section{Sampling strategy}

For all four components, we purposively selected two counties where all three diseases of interest (LF, onchocerciasis and schistosomiasis) are endemic, where the population resides in predominantly rural areas (reflecting the majority of the Liberian population) and from different geographical regions of Liberia. The selected counties, Bong in Central Liberia and Maryland in South-east Liberia, have similar levels of household wealth across all quintiles, although Bong has higher, and Maryland lower, illiteracy levels compared to the national average [9]. Bong had higher EVD cases than Maryland, with health systems and communities consequently more badly affected by the epidemic. The NTD burden, and geographic and therapeutic program coverage also varies between the two counties.

Within each county, we used a multi-stage sampling process (Fig. 1) [13]. First, we randomly selected three districts, then we randomly selected three communities from each district, yielding nine communities per county. Once communities had been identified, the sample selection process was different for each study component. For the HHS, we obtained a list of all households from the community head and randomly selected 29 households per community. CDDs are attached to the community with each one covering a $5-\mathrm{km}$ radius for their work. We planned to select all CDDs from the 18 communities for inclusion in the CDD CS and to identify up to 10 CDDs (six Bong, four Maryland) to participate in the CDD TM, based on those actively conducting MDA during the time that the research team was in the community. For component four (KIS), we aimed to select up to 15 key informants per county, including health workers

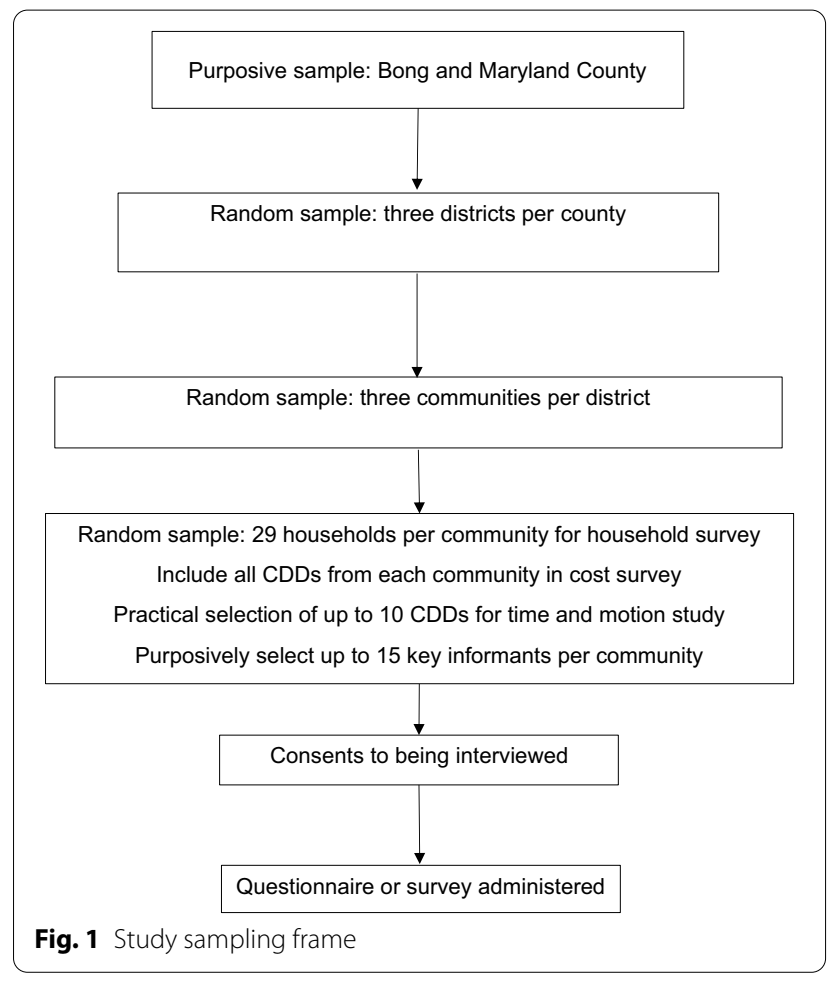

and community leaders. We aimed to include different types of health workers of different genders and experiences within practical constraints such as availability and willingness to participate. The target sample size and the number achieved are shown by study component in Table 1.

\section{Data collection and analysis}

We assigned a team leader and four enumerators to one community at a time to collect data for each study component on Android tablets using Survey CTO, between November 2017 and June 2018.

\section{Household survey (HHS)}

We conducted interviews with consenting household heads using a questionnaire containing open and closed-ended questions to collect data on knowledge about NTDs and MDA; accessibility and adherence to MDA; MDA drug acceptance; and information sources on MDA. Survey data were analysed to produce indicators of NTD awareness (heard or not heard of NTDs); MDA awareness (as for NTD); whether the respondent took MDA tablets in the last round and if not why; and to identify the most important sources of information on MDA by county and gender. 
Table 1 Respondent type, inclusion criteria, target and actual sample size by study component

\begin{tabular}{|c|c|c|c|c|c|c|c|c|}
\hline \multirow[t]{3}{*}{ Study component } & \multirow[t]{3}{*}{ Respondent type } & \multirow[t]{3}{*}{ Inclusion criteria } & \multicolumn{6}{|c|}{ Sample size } \\
\hline & & & \multicolumn{3}{|l|}{ Target } & \multicolumn{3}{|c|}{ Actual } \\
\hline & & & Bong & Maryland & Total & Bong & Maryland & Total \\
\hline $\begin{array}{l}1 \text { Household MDA access and } \\
\text { adherence survey (HHS) }\end{array}$ & Household members & $\begin{array}{l}\text { Lived in community during last } \\
\text { MDA round }{ }^{\mathrm{a}}\end{array}$ & 260 & 260 & 520 & 261 & 263 & 524 \\
\hline 3 CDD cost survey (CDD CS) & CDDs & $\begin{array}{l}\text { Assigned to the sampled com- } \\
\text { munity }\end{array}$ & 15 & 14 & 29 & 9 & 15 & 24 \\
\hline $\begin{array}{l}2 \text { CDD time and motion study } \\
\text { (CDD TM) }\end{array}$ & CDDs & Participated in last MDA round & 15 & 14 & 29 & 6 & 4 & 10 \\
\hline 4 Key informant survey (KIS) & $\begin{array}{l}\text { Health workers, community } \\
\text { health workers and community } \\
\text { leaders }\end{array}$ & $\begin{array}{l}\text { Works in/assigned to the sam- } \\
\text { pled community }\end{array}$ & 18 & 12 & 30 & 15 & 13 & 28 \\
\hline
\end{tabular}

${ }^{a}$ Last MDA round included Onco and LF (Maryland) and LF (Bong)

\section{Capturing and analysing CDD costs (CDD CS and CDD TM)} For the CDD CS, we used a questionnaire containing open and closed-ended questions on involvement in MDA activities including CDDs role and experience in training, collection and distribution of drugs, costs incurred, days worked in the MDA, monthly salaries for their main occupation and any allowances received for MDA participation. Direct costs incurred by CDDs during the last MDA round were calculated by summing all reported expenditure on food and transportation costs during MDA training and drug distribution. Direct costs, minus allowances reported, were used to calculate net direct costs [14]. CDD opportunity cost was calculated by multiplying the number of days worked on MDA activities by the value of their time. CDD time was valued using three alternative indicators. Firstly, we used the CDDs' reported wage or salary for their main occupation to impute their daily wage (imputed daily wage [IDW]). We also obtained data on the Liberian minimum wages for unskilled workers and, separately, civil servants [15] which we considered skilled workers. These rates were converted to two daily wage rates, minimum daily wage unskilled (MDWU) and skilled (MDWS). The total cost to CDDs per MDA round was calculated by summing the net direct costs and the estimated opportunity cost [14]. Results are presented as means and medians for the sampled CDDs.

The CDD TM was an observational study where the enumerators followed consenting CDDs during their household rounds using a stopwatch to record the time spent on each separate task in each household. Tasks were coded into a sub-set of the five most reported tasks and then used to calculate the time spent on different tasks, the mean time and CDD opportunity cost per house visited using MDWU and MDWS.
All cost data were in Liberian dollars and converted to US dollars using the 2018 exchange rate $(1 \mathrm{LRD}=0.0050$ USD) [16]. We cleaned and analysed all quantitative data in Excel [17]

\section{Qualitative data collection and analysis (KIS)}

The KIS included questions about the organisation and management of the MDA in the communities with a focus on resource use and constraints. Both the KIS and CDD CS contained open-ended questions which enabled respondents to provide free-text responses. In addition, the survey drew on the experiences and comments of the researcher, including critical reflections from their interactions with the CDDs' key informants. We collated and reviewed all free-text data for key themes related to resources needed to implement MDA. We used a framework approach to identify emerging themes from the open-ended questions and critical reflection data [18]. This involved (i) reviewing the data to identify emerging themes, both inductively and deductively, based on emerging findings from the quantitative analysis; (ii) generating a coding framework to apply to the data based on emerging themes; (iii) applying the coding framework and charting the data to identify synergies between themes; and (iv) synthesising findings at a higher level linked to demand-and supply-side factors as presented in the results [18] (Additional file 1: Table S1).

\section{Results \\ Descriptive statistics}

For the HHS, we obtained 524 (261 Bong, 263 Maryland) household head interviews ( $51 \%$ male, $49 \%$ female) with just over half (53\%) coming from the 26-49 age group. Twenty-four CDDs (nine Bong, 15 Maryland) completed the CDD CS, with females making up $25 \%$ of the total sample. Ten CDDs (six Bong, four Maryland) were 
observed for the CDD TM with only one of these being female. Twenty-eight respondents (15 Bong, 13 Maryland) completed the KIS with $39 \%$ female (Table 2).

\section{Household accessibility and adherence to MDA (HHS)}

More respondents were aware of MDA than NTD in both counties (heard of NTD 13\% vs heard of MDA $44 \%$, and $4 \%$ vs $25 \%$ Bong and Maryland, respectively). Awareness of NTD in Bong was $8 \%$ among males and $17 \%$ among females, while in Maryland, it was $5 \%$ and $2 \%$, respectively. Awareness of MDA in Bong was $43 \%$ and $46 \%$ (males and females, respectively) and $24 \%$ and $26 \%$, respectively, in Maryland. (It is important to note the above results reflect the diverse ways that NTDs and MDA are referred to in the communities and that MDA was a relatively new concept for some communities, e.g., schistosomiasis in Maryland; this diversity may not have been fully reflected in our standardised survey tools.) A lower proportion of males and females reported taking tablets during MDA in Bong than Maryland (Bong 40\% male and $40 \%$ female, vs Maryland $57 \%$ and $55 \%$, respectively). The main reason for males and females reporting not taking the tablet in Bong was not being informed about the MDA activities ( male $=22 \%$, female $=24 \%$, both sexes $=23 \%$ ). In Maryland, for males, it was due to not being informed (9\%) or being absent during the MDA activities (female $=20 \%$ and both sexes $=14 \%$ ). The most cited sources of MDA information in both counties (and sexes) were town criers (Table 3 ).

\section{Estimated costs incurred by CDDs throughout the MDA round}

The mean reported direct costs incurred by CDDs during the MDA round was $\$ 4.17$ (median $\$ 2.00$, range $\$ 0.00$ to 15.00$)$. Reported mean allowance received per CDD/round was $\$ 15.27$ ( $\$ 16.50, \$ 0.00$ to $\$ 30.00$ ), resulting in a mean net income of $\$ 11.10$ per CDD/ round $(\$ 8.13,-\$ 4.00$ to $\$ 30.00)$. Mean reported CDD monthly salary was $\$ 29.27$, yielding an imputed daily wage rate of $\$ 1.13$ ( $\$ 0.04, \$ 0$ to $\$ 12.12$ ). Multiplying the mean reported number of days spent on MDA activity per round per CDD (mean 16.04, median 14, range 2 to 33) by the imputed daily wage rate, minimum daily wage for unskilled and, separately, skilled workers, yields estimated mean indirect costs incurred per CDD per MDA round of $\$ 23.00$ ( $\$ 0.27, \$ 0.00$ to $\$ 169.62)$ ), $\$ 12.90$ (\$11.26, $\$ 1.61$ to $\$ 26.53$ ) or $\$ 23.15$ (\$20.20, \$2.89 to \$47.62). Subtracting the indirect costs from the net direct income (or expenditure if negative) shows that mean cost to CDDs of participating in the MDA round was $-\$ 11.90$ ( $\$ 5.04,-\$ 169.62$ to $\$ 30.00)$, $-\$ 1.79$ ( $\$ 3.12,-\$ 24.53$ to $\$ 22.37)$ or $-\$ 12.05$ ( $-\$ 6.15$, $-\$ 45.62$ to $\$ 17.9$ ) using the IDW, MDWU and MDWS time valuation methods (negative sign implies cost, positive is income gain), respectively (Table 4).

\section{Household and opportunity costs incurred by all observed CDDs per household visited during MDA (CDD TM)}

We observed 10 CDDs for a total of $4645 \mathrm{~min}$ in which they undertook 271 household visits to deliver MDA. CDDs conducted a range of tasks with 'Measuring and drug administration' taking the most time (mean $8.24 \mathrm{~min}$ ) followed by 'record-keeping and registration' (mean $5.14 \mathrm{~min}$ ). The mean time per household visited was $17.14 \mathrm{~min}$. (Table 5). Using the MDWU and MDWCS to value this time yields an opportunity cost to the CDD of \$0.03-0.05 per house visited.

\section{Qualitative findings on community-level resource use and constraints for MDA delivery (KIS)}

Key informants in both counties reported that drugs for MDA were supplied by the government and nongovernmental organisations (NGOs) and confirmed that the communities bore no costs for drug purchase and transportation. Bong reported the use of wooden and cemented buildings for community-level MDA meetings, while Maryland reported no buildings used for the running of the MDA program. Bong reported the use of three NGO-rented motorcycles during MDA, while Maryland reported using two government-rented motorcycles. Other equipment used in both counties included generators, flip charts, audio and video equipment, megaphones and measuring sticks.

Respondents cited several demand-side challenges to effective MDA such as the important role of community leaders in supporting MDA and identified challenges around expectations for communities to provide 'compensation' to CDDs, concerns over side effects, and trust issues. On the supply side, challenges to effective MDA delivery included shortages and delays in medicine availability; frustration among CDDs particularly concerning costs and poor compensation; and reporting challenges (Additional file 1: Table S1) [19].

\section{Discussion}

This study used mixed (quantitative and qualitative) methods to identify and explore community (demandside) and health system (supply-side) challenges which could potentially affect MDA coverage.

Our results showed low levels of awareness about MDA and lower levels of awareness of NTDs in both counties. We found that $48 \%$ of people reported taking the MDA tablets during the last round, with the most common reasons for not adhering being because they were not around when it was being delivered or were 
Table 2 Descriptive statistics by study component

\begin{tabular}{|c|c|c|c|c|c|c|c|c|}
\hline \multirow[t]{2}{*}{ Study component } & \multirow[t]{2}{*}{ Indicator } & \multirow[t]{2}{*}{ Category } & \multicolumn{2}{|c|}{ Bong } & \multicolumn{2}{|c|}{ Maryland } & \multicolumn{2}{|c|}{ Total } \\
\hline & & & $N$ & $\%$ & $N$ & $\%$ & $N$ & $\%$ \\
\hline \multirow{11}{*}{$\begin{array}{l}\text { 1. Household MDA access and adherence } \\
\text { survey }(\mathrm{HHS})\end{array}$} & \multirow[t]{3}{*}{ Gender } & Male & 130 & 50 & 136 & 52 & 266 & 51 \\
\hline & & Female & 131 & 50 & 127 & 48 & 258 & 49 \\
\hline & & Total & 261 & 100 & 263 & 100 & 524 & 100 \\
\hline & \multirow[t]{5}{*}{ Age } & $18-25$ & 20 & 8 & 11 & 4 & 31 & 6 \\
\hline & & $26-49$ & 136 & 52 & 140 & 53 & 276 & 53 \\
\hline & & Over 49 & 74 & 28 & 85 & 32 & 159 & 30 \\
\hline & & Not disclosed & 31 & 12 & 27 & 10 & 58 & 11 \\
\hline & & Total & 261 & 100 & 263 & 100 & 524 & 100 \\
\hline & \multirow[t]{3}{*}{ Disability status ${ }^{\mathrm{a}}$} & Disability & 28 & 11 & 26 & 10 & 54 & 10 \\
\hline & & No disability & 233 & 89 & 237 & 90 & 470 & 90 \\
\hline & & Total & 261 & 100 & 263 & 100 & 524 & 100 \\
\hline \multirow[t]{11}{*}{ 2. CDD cost survey (CDD CS) } & \multirow[t]{3}{*}{ Gender } & Male & 8 & 88.9 & 10 & 66.7 & 18 & 75 \\
\hline & & Female & 1 & 11.1 & 5 & 33.3 & 6 & 25 \\
\hline & & Total & 9 & 100 & 15 & 100 & 24 & 100 \\
\hline & \multirow[t]{8}{*}{ Occupation } & Farming & 4 & 44.4 & 2 & 13.3 & 6 & 25 \\
\hline & & Forest ranger & 0 & 0 & 1 & 6.7 & 1 & 4.1 \\
\hline & & Retired nurse & 1 & 11.1 & 0 & 0 & 1 & 4.1 \\
\hline & & Student & 0 & 0 & 6 & 40 & 6 & 25 \\
\hline & & Teacher & 2 & 22.2 & 2 & 13.3 & 4 & 16.7 \\
\hline & & Volunteer & 1 & 11.1 & 3 & 20 & 4 & 16.7 \\
\hline & & Business & 1 & 11.1 & 1 & 6.7 & 2 & 8.3 \\
\hline & & Total & 9 & 100 & 15 & 100 & 24 & 100 \\
\hline \multirow[t]{8}{*}{ 3. CDD time and motion study (CDD TM) } & \multirow[t]{8}{*}{ Occupation } & Farming & 2 & 33.3 & 1 & 30 & 3 & 30 \\
\hline & & Forest ranger & 0 & 0 & 1 & 0 & 1 & 10 \\
\hline & & Retired nurse & 1 & 16.7 & 0 & 20 & 1 & 10 \\
\hline & & Student & 1 & 16.7 & 1 & 0 & 2 & 20 \\
\hline & & Teacher & 0 & 0 & 1 & 0 & 1 & 10 \\
\hline & & Volunteer & 1 & 16.7 & 0 & 50 & 1 & 10 \\
\hline & & Business & 1 & 16.7 & 0 & 0 & 1 & 10 \\
\hline & & Total & 6 & 100 & 4 & 100 & 10 & 100 \\
\hline \multirow[t]{9}{*}{ 4. Key informant survey (KIS) } & \multirow[t]{3}{*}{ Gender } & Male & 9 & 60 & 8 & 62 & 17 & 61 \\
\hline & & Female & 6 & 40 & 5 & 38 & 11 & 39 \\
\hline & & Total & 15 & 100 & 13 & 100 & 28 & 100 \\
\hline & \multirow[t]{6}{*}{ Role } & Town chief & 5 & 33 & 4 & 31 & 9 & 32 \\
\hline & & District Surveillance Officer & 1 & 7 & 0 & 0 & 1 & 4 \\
\hline & & Community Health Surveillance Supervisor & 4 & 27 & 5 & 38 & 9 & 32 \\
\hline & & Officer in charge & 5 & 33 & 1 & 8 & 6 & 21 \\
\hline & & Community Development Chairperson & 0 & 0 & 3 & 23 & 3 & 11 \\
\hline & & Total & 15 & 100 & 13 & 100 & 28 & 100 \\
\hline
\end{tabular}

${ }^{a}$ Disability status was defined using the Washington group of questions on the difficulty in carrying out basic activities (seeing, hearing, walking, self-care, cognition and communication)

not informed about the delivery. This emphasises the importance of ensuring MDA timing and organisation is cognisant of daily and seasonal activities in specific communities [19-22]. As part of the capacity- and awareness-building target of the NTD roadmap to 2030, awareness-generation activities to educate and inform the endemic communities are deemed essential [10], and positive community leader influence and community trust is vital for effective healthcare delivery [23]. Indeed, we found that community leaders encouraged the community to listen to the message from town criers, which was where most respondents reported 
Table 3 Knowledge of and adherence to NTDs and MDA for Bong and Maryland, Liberia

\begin{tabular}{|c|c|c|c|c|c|c|c|c|c|c|c|c|c|c|c|}
\hline \multirow[t]{3}{*}{ Knowledge/adherence } & \multirow[t]{3}{*}{ Responses and sub-totals } & \multicolumn{6}{|c|}{ Bong } & \multicolumn{6}{|c|}{ Maryland } & \multirow{2}{*}{\multicolumn{2}{|c|}{$\begin{array}{l}\text { Grand } \\
\text { total }\end{array}$}} \\
\hline & & \multicolumn{2}{|c|}{ Male } & \multicolumn{2}{|c|}{ Female } & \multicolumn{2}{|c|}{ Total } & \multicolumn{2}{|l|}{ Male } & \multicolumn{2}{|c|}{ Female } & \multicolumn{2}{|l|}{ Total } & & \\
\hline & & $N$ & $\%$ & $N$ & $\%$ & $N$ & $\%$ & $N$ & $\%$ & $N$ & $\%$ & $N$ & $\%$ & $N$ & $\%$ \\
\hline \multirow[t]{4}{*}{ NTD awareness } & Heard of NTD & 11 & 8 & 22 & 17 & 33 & 13 & 7 & 5 & 3 & 2 & 10 & 4 & 43 & 8 \\
\hline & Not heard of NTD & 100 & 77 & 101 & 78 & 201 & 77 & 108 & 79 & 120 & 94 & 228 & 87 & 429 & 82 \\
\hline & Missing $^{b}$ & 19 & 15 & 6 & 5 & 27 & 10 & 21 & 15 & 4 & 3 & 25 & 10 & 52 & 10 \\
\hline & Total & 130 & 100 & 129 & 100 & 261 & 100 & 136 & 100 & 127 & 100 & 263 & 100 & 524 & 100 \\
\hline \multirow[t]{4}{*}{ MDA awareness } & Heard of MDA & 56 & 43 & 59 & 46 & 115 & 44 & 33 & 24 & 33 & 26 & 66 & 25 & 181 & 35 \\
\hline & Not heard of MDA & 55 & 42 & 64 & 50 & 119 & 46 & 81 & 60 & 89 & 70 & 170 & 65 & 289 & 55 \\
\hline & Missing $^{b}$ & 19 & 15 & 6 & 5 & 27 & 10 & 22 & 16 & 5 & 4 & 27 & 10 & 54 & 10 \\
\hline & Total & 130 & 100 & 129 & 100 & 261 & 100 & 136 & 100 & 127 & 100 & 263 & 100 & 524 & 100 \\
\hline \multirow[t]{10}{*}{ Took tablets during recent MDA round } & Yes & 52 & 40 & 51 & 40 & 103 & 39 & 77 & 57 & 70 & 55 & 147 & 56 & 250 & 48 \\
\hline & No & \multicolumn{14}{|c|}{ Reason for not taking tablet during recent MDA round } \\
\hline & Absent & 16 & 12 & 10 & 8 & 26 & 10 & 11 & 8 & 25 & 20 & 36 & 14 & 62 & 12 \\
\hline & Do not know & 2 & 2 & 2 & 2 & 4 & 2 & 9 & 7 & 8 & 6 & 17 & 6 & 21 & 4 \\
\hline & Not informed & 28 & 22 & 31 & 24 & 59 & 23 & 12 & 9 & 4 & 3 & 16 & 6 & 75 & 14 \\
\hline & Pregnant & 0 & 0 & 7 & 5 & 7 & 3 & 0 & 0 & 5 & 4 & 5 & 2 & 12 & 2 \\
\hline & Sick & 0 & 0 & 1 & 1 & 1 & 0 & 1 & 1 & 1 & 1 & 2 & 1 & 3 & 1 \\
\hline & Other & 13 & 10 & 22 & 17 & 35 & 13 & 6 & 4 & 12 & 9 & 18 & 7 & 53 & 10 \\
\hline & Missing $^{b}$ & 19 & 15 & 5 & 4 & 26 & 10 & 20 & 15 & 2 & 2 & 22 & 8 & 48 & 9 \\
\hline & Total & 130 & 100 & 129 & 100 & 261 & 100 & 136 & 100 & 127 & 100 & 263 & 100 & 524 & 100 \\
\hline \multirow[t]{4}{*}{ Source of information on $\mathrm{MDA}^{\mathrm{a}}$} & Town crier & 81 & 59 & 81 & 60 & 162 & 59 & 60 & 41 & 72 & 59 & 132 & 49 & 294 & 54 \\
\hline & Radio & 32 & 23 & 33 & 24 & 65 & 24 & 35 & 24 & 18 & 15 & 53 & 20 & 118 & 22 \\
\hline & Hospital & 25 & 18 & 21 & 16 & 46 & 17 & 52 & 35 & 32 & 26 & 84 & 31 & 130 & 24 \\
\hline & Total & 138 & 100 & 135 & 100 & 273 & 100 & 147 & 100 & 122 & 100 & 269 & 100 & 542 & 100 \\
\hline
\end{tabular}

a Some respondents cited more than one option, which is why totals are different from other indicators

${ }^{\mathrm{b}}$ Missing or no data

getting information from in the household survey. More could be done to enhance the role of community leaders in supporting MDA, which should, in turn, generate trust and community ownership of MDA, with likely benefits for coverage and adherence [24-26].

We found that the Liberian CDDs spent an average of 16.04 workdays in the MDA round, similar to the 13.31 workdays a year on NTD activities including MDA in Uganda [27]. Our quantitative findings indicate that Liberian CDDs incurred direct and opportunity costs for taking part in MDA and that for some CDDs, these costs were not adequately compensated by allowances, resulting in a mean cost to CDDs of $\$ 11.90$. Placing this into context, the minimum monthly wage for civil servants in Liberia is $\$ 37.52$ (5600 Liberian dollars). This led to frustration among CDDs, which were reflected in our qualitative findings and have been identified in other settings $[11,26-28]$.

From our KIS survey, we discovered that communities were expected to compensate CDDs via providing gifts in kind such as a cup of rice or a small fee in exchange for medicines to CDDs. Some health staff described that community members were often unable or unwilling to do this due to their level of income and/or socioeconomic status and so avoided the CDD. With the high incidence of extreme poverty in the communities receiving MDA and possible deterrence [29-31], this leads us to question the viability of such an approach on equity and efficiency grounds and a potential risk to the achievement of NTD targets on equitable access to healthcare [10]

Our observations of CDDs during their MDA activities identified that two tasks accounted for a large proportion of their time, namely measuring and drug administration, and record-keeping and registration. However, qualitative findings indicated that transportation for CDDs was also a challenge, and they found it difficult to move within communities to distribute drugs. Motorcycles were limited and insufficient to reach out and serve communities, making the workload greater for CDDs as they walked longer distances, taking up more time to distribute drugs and incurring higher direct and opportunity costs by the 


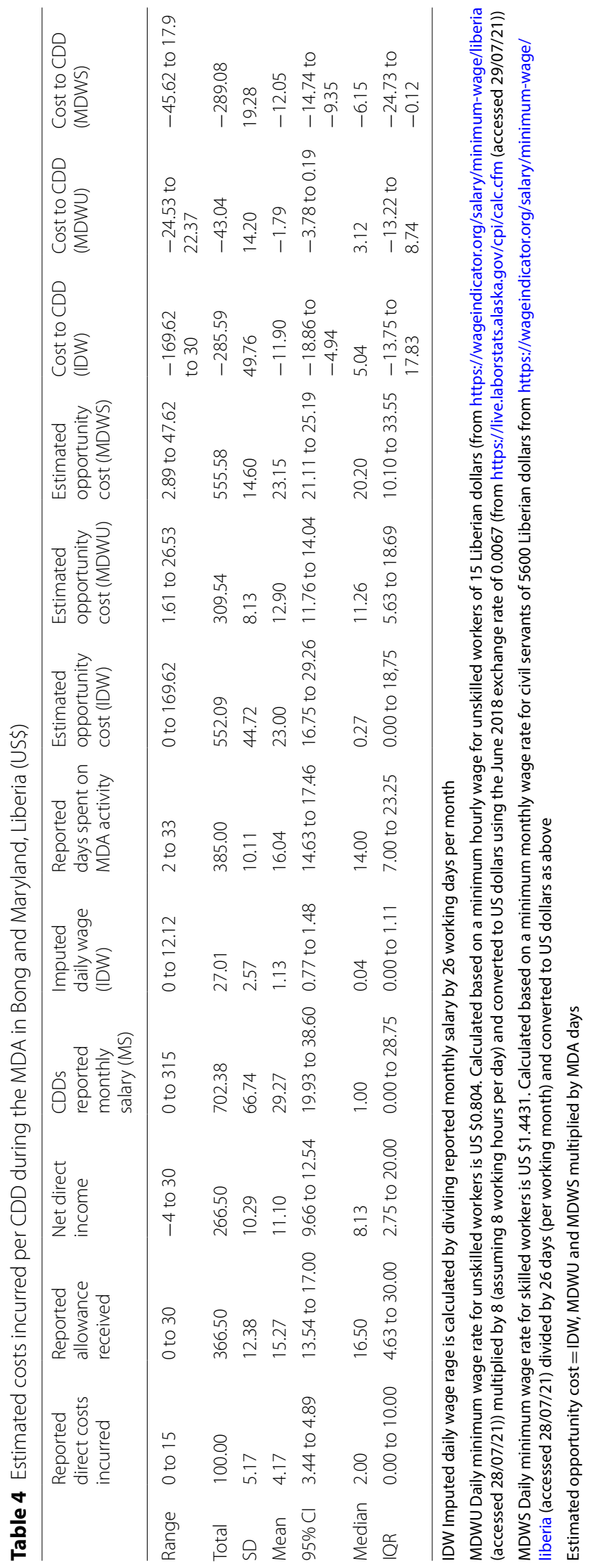


Table 5 Time and opportunity cost by CDDs per MDA household, in Bong and Maryland, Liberia

\begin{tabular}{|c|c|c|c|c|c|c|c|c|}
\hline \multirow[t]{2}{*}{ CDD identifier } & \multicolumn{6}{|c|}{ Task (time in minutes) } & \multirow{2}{*}{$\begin{array}{l}\text { Total time } \\
\text { (all tasks) }\end{array}$} & \multirow{2}{*}{$\begin{array}{l}\text { House visits } \\
\text { observed } \\
(n)\end{array}$} \\
\hline & $\begin{array}{l}\text { Measuring } \\
\text { and drug } \\
\text { administration }\end{array}$ & Walking & Greetings & $\begin{array}{l}\text { Health/ } \\
\text { awareness } \\
\text { talks }\end{array}$ & $\begin{array}{l}\text { Record-keeping } \\
\text { and registration }\end{array}$ & Other & & \\
\hline A & 209 & 0 & 105 & 49 & 217 & 19 & 599 & 25 \\
\hline B & 422 & 2 & 36 & 117 & 133 & 22 & 732 & 25 \\
\hline C & 241 & 48 & 0 & 61 & 176 & 0 & 526 & 29 \\
\hline D & 271 & 9 & 3 & 1 & 147 & 0 & 431 & 30 \\
\hline$E$ & 354 & 18 & 37 & 102 & 101 & 7 & 619 & 27 \\
\hline$F$ & 114 & 28 & 0 & 40 & 114 & 7 & 303 & 25 \\
\hline G & 271 & 69 & 7 & 40 & 272 & 7 & 666 & 52 \\
\hline $\mathrm{H}$ & 156 & 25 & 2 & 79 & 115 & 11 & 388 & 29 \\
\hline । & 182 & 41 & 5 & 17 & 114 & 0 & 359 & 28 \\
\hline J & 12 & 0 & 1 & 5 & 4 & 0 & 22 & 1 \\
\hline Total (all CDDs) & 2232 & 240 & 196 & 511 & 1393 & 73 & 4645 & 271 \\
\hline Total time per task (mean) & 223.2 & 24 & 19.6 & 51.1 & 139.3 & 7.3 & 464.5 & 27.1 \\
\hline Time per household by task (mean) & 8.24 & 0.89 & 0.72 & 1.89 & 5.14 & 0.27 & 17.14 & na \\
\hline Opportunity cost MDWU (mean) (\$) & 0.01 & 0.001 & 0.001 & 0.003 & 0.008 & 0.0004 & 0.03 & na \\
\hline Opportunity cost MDWCS (mean) (\$) & 0.02 & 0.002 & 0.002 & 0.005 & 0.015 & 0.0008 & 0.05 & na \\
\hline
\end{tabular}

NB: stopwatch data were recorded in full minutes; na: not applicable. A-J represent anonymised individual CDDs

end of the MDA. Support to compensate CDDs for the costs incurred during their role in MDA delivery and for more efficient transport would likely bring benefits in terms of greater satisfaction and retention, supporting the NTD road map for 2021-2030 [10].

Creating awareness and educating households on MDA and its benefits and side effects of drugs was relatively time-consuming for CDDs at each household. Hence, low awareness increased the workload and consequently the opportunity cost incurred by the CDDs in our study and in others $[21,26]$. CDDs could be better supported during MDA with access to materials to support conversations about the reasons for the MDA and drug safety information to reassure households [24, 32, 33].

Having an adequate supply of quality-assured medicines and an efficient supply chain at the community level is critical for the effective allocation and distribution of medicines. However, as in other studies, we found that drug shortages made it difficult for CDDs to effectively distribute drugs to the target population [34]. Similarly, delayed distribution due to drug shortages confused both CDDs and the communities, hampering adherence when the MDA happened [24]. Furthermore, even though most CDDs attended at least one training session, many had limited training on how to complete reporting forms, and consequently, they submitted incomplete records which in turn compromised programmatic-level medicine estimates [35]. These findings highlight the critical importance of NTD monitoring and evaluation mechanisms and suggest that investment in improved CDD training may yield programmatic benefits [10].

Recall bias is inherent in any study relying on household surveys, and this study is no exception. The recruitment of female CDDs was challenging due to fewer females acting as CDDs in the study communities because of preexisting gender norms, competing domestic priorities, and reduced literacy levels compared to their male counterparts $[29,30]$. We also faced capacity challenges that affected the quality of some of the data collected. Analysis of the household survey results on NTD and MDA awareness revealed many missing or no responses. On investigation, it was found that this was due to confusion and lack of understanding of the diverse range of definitions and local terminologies used to refer to NTDs and MDA in the different communities. Unfortunately, due to internet connectivity problems and the community process of data collection, this was not picked up until it was too late to alter the survey tool. This may have led to an underestimate of NTD and MDA awareness in our study.

MDA activities were measured in this study by following the CDDs and using a stopwatch to record time spent on each activity. Unfortunately, time spent by CDDs in houses was only recorded in minutes (not minutes and seconds) which may have affected results. In Uganda, a similar study used pictures and drawings to describe the entire day of the CDD during NTD activities, bringing in more context to the opportunity costs borne by these CDDs [27]. This approach might have worked well in the 
Liberian context; however, it would not have yielded a quantitative estimate of costs per house, highlighting the benefits of complementary quantitative and qualitative research in understanding health systems.

The data collection limitations of this study highlight the need for continued investment in health research capacity strengthening in low- and middle-income countries. Nevertheless, this work represents a first effort at conducting a mixed-methods health economic study of NTDs in Liberia and thus a major step forward in health systems research for the country.

\section{Conclusion}

Community drug distributors are the interface between the supply- and demand-sides of the health system during MDA and appear to face challenges from both sides. Improved remuneration to meet opportunity cost of MDA participation would likely help to address this and further strengthening the community-level health systems.

\author{
Abbreviations \\ NTD: Neglected tropical diseases; MDA: Mass drug administration; CDD: \\ Community drug distributors; LF: Lymphatic filariasis; IVM: Ivermectin; ABD: \\ Albendazole; HHS: Household survey; CDD CS: Community drug distributor \\ cost survey; CDD TM: Community drug distributor time and motion study; KIS: \\ Key informant survey.
}

\section{Supplementary Information}

The online version contains supplementary material available at https://doi. org/10.1186/s13071-021-05058-w.

Additional file 1: Table S1. Supply- and demand-side challenges identified by CDDs, key informants in free-text survey responses and via researcher observations, Bong and Maryland, Liberia.

\section{Acknowledgements}

We thank and acknowledge all the households, CDDs and key informants who gave up more of their valuable time to participate in the study. The authors would also like to thank the community leaders of Bong and Maryland for their guidance and facilitation of data collection. The entire COUNTDOWN team at the Liverpool School of Tropical Medicine and the University of Liberia-Pacific Institute of Research and Evaluation were supportive in the development and implementation of this study. Finally, we would like to thank UKAID within the UK Foreign Office for their generous support for this study.

\section{Authors' contributions}

$E A, F S, L D, A S, R T, K K$ and EW conceived the study. EW and FS designed the analysis. FS and AS collected data. EA, LD and EW analysed the data. EA and EW drafted the manuscript. KK and RT reviewed the context of the manuscript. All authors read and approved the final manuscript.

\section{Funding}

This study was funded by COUNTDOWN (Calling time on Neglected Tropical Diseases) funded by UKAID within the UK Foreign Office, Award ID PO 6407.

\section{Availability of data and materials}

The dataset supporting the conclusions of this article is available on request from the authors.

\section{Declarations}

\section{Ethics approval and consent to participate}

Before commencing the study, we obtained ethical approval for the study from the Liverpool School of Tropical Medicine, UK (Protocol Number: 16-061) and the University of Liberia-Pacific Institute of Research and Evaluation Institutional Review Board (UL-PIRE IRB) (Protocol Number 17-02-027). We also obtained written informed consent from all adult participants before interviews were conducted.

\section{Consent for publication}

All authors consented to the publication of this paper.

\section{Competing interests}

The authors declare that they have no competing interests.

\section{Author details}

${ }^{1}$ Department of Vector Biology, Liverpool School of Tropical Medicine, Pembroke Street, Liverpool L3 5 QA, UK. ${ }^{2}$ University of Liberia, Pacific Institute for Research and Evaluation (UL-PIRE), Capitol Hill, Monrovia, Liberia. ${ }^{3}$ Department of International Public Health, Liverpool School of Tropical Medicine, Pembroke Street, Liverpool L3 5 QA, UK. ${ }^{4}$ Department of Tropical Disease Biology, Liverpool School of Tropical Medicine, Pembroke Street, Liverpool L3 5 QA, UK. ${ }^{5}$ Ministry of Health, SKD Boulevard, Monrovia, Liberia.

Received: 9 February 2021 Accepted: 7 October 2021

Published online: 28 October 2021

\section{References}

1. Lee BY, Bartsch SM, Gorham KM. Economic and financial evaluation of neglected tropical diseases. Adv Parasitol. 2015;87:329-417.

2. Deribe K, Meribo K, Gebre T, Hailu A, Ali A, Aseffa A, et al. The burden of neglected tropical diseases in Ethiopia, and opportunities for integrated control and elimination. Parasit Vectors. 2005;5:240.

3. Aagaard H, Chaignat CL. Neglected tropical diseases: Equity and social determinants. In: Blas E, Kurup SA, editors. Equity, social determinants and public health programmes. Geneva: World Health Organization; 2010. p. $135-57$.

4. Program TD. 2015-16 Liberia demographic and health survey, summary report. Liberia, 2016.

5. Conteh L, Engels T, Molyneux D. Socioeconomic aspects of neglected tropical diseases. Lancet. 2010;375:239-47.

6. Dean L, Ozano K, Adekeye O, Dixon R, Fung EG, Gyapong M, et al. Neglected tropical diseases as a 'litmus test'for Universal Health Coverage? Understanding who is left behind and why in Mass Drug Administration: lessons from four country contexts. PLOS NTD. 2019;13(11):e0007847.

7. Ministry of Health and Social Welfare. Master plan for integrated neglected tropical diseases program (NTDs). Monrovia: Republic of Liberia; 2011.

8. Ministry of Health. Liberia—Post EVD NTD/eye health/NCD readiness assessment report. Monrovia: Republic of Liberia; 2015.

9. Ministry of Health Liberia. Liberia demographic and health survey, summary report. Monrovia: Republic of Liberia; 2016.

10. Ministry of Health Liberia. Liberia demographic and health survey, summary report. Monrovia: Republic of Liberia; 2020.

11. Bogus J, Gankpala L, Fischer K, Krentel A, Weil GJ, Fischer PU, et al. Community attitudes toward mass drug administration for control and elimination of neglected tropical diseases after the 2014 outbreak of Ebola virus disease in Lofa county, Liberia. Am J Trop Med Hyg. 2015;2(9637):497-503.

12. Thomas BC, Kollie K, Koudou B, Mackenzie C. Commentary: restarting NTD programme activities after the Ebola outbreak in Liberia. Infect Dis Poverty. 2017;6(1):1-4.

13. Sedgwick P. Multistage sampling. BMJ. 2015;351:h4155.

14. Drummond MF, Sculpher MJ, Claxton K, Stoddart GL, Torrance GW. Methods for the economic evaluation of health care programmes. Oxford: Oxford University Press; 2015. 
15. https://www.minimum-wage.org/international/liberia. Accessed 28 July 2021.

16. https://www.xe.com/currencyconverter/convert/?Amount=1\&From= USD\&To=LRD. Accessed 28 July 2021.

17. https://www.microsoft.com/en-gb/p/excel. Accessed 15 Jan 2020.

18. Ritchie J, Lewis J. Qualitative research practice: a guide for social science students and researchers. London: Sage; 2013.

19. Krentel A, Damayanti R, Titaley CR, Suharno N, Bradley M, Lynam T. Improving coverage and compliance in mass drug administration for the elimination of LF in two 'endgame' districts in Indonesia using micronarrative surveys. PLoS NTD. 2016;10(11):e0005027.

20. Dembele M. The ingredients of a successful MDA approach in Bamako, Mali. In: Proceedings of the 2017 COR-NTD meeting, Baltimore, MD, USA, 2017.

21. Njomo DW, Mukoko DA, Nyamongo NK, Karanja J. Increasing coverage in mass drug administration for lymphatic filariasis elimination in an urban setting: a study of Malindi Town, Kenya. PLoS ONE. 2014;9(1):e83413.

22. Nandha B, Sadanandane C, Jambulingam P, Das PK. Delivery strategy of mass annual single dose DEC administration to eliminate lymphatic filariasis in the urban areas of Pondicherry, South India: 5 years of experience. Filaria J. 2007;6(1):7.

23. Report WGM. How much do people in Africa trust medical experts and vaccines? Landmark survey reveals public confidence in health, science, and vaccines across the continent. Welcome Trust. 2019.

24. Krentel A, Fischer PU, Weil GJ. A review of factors that influence individual compliance with mass drug administration for elimination of lymphatic filariasis. PLoS Negl Trop Dis. 2013:7(11):e2447.

25. Silumbwe A, Zulu JM, Halwindi H, Jacobs C, Zgambo J, Dambe R, et al. A systematic review of factors that shape implementation of mass drug administration for lymphatic filariasis in sub-Saharan Africa. BMC Public Health. 2017:17(1):484-484.

26. Yirga D, Deribe K, Woldemichael K, Wondafrash M, Kassahun W. Factors associated with compliance with community directed treatment with ivermectin for onchocerciasis control in Southwestern Ethiopia. Parasit Vectors. 2010;3(1):48.

27. Fleming FM, Matovu F, Hansen K, Webster JP. A mixed methods approach to evaluating community drug distributor performance in the control of neglected tropical diseases. Parasit Vectors. 2016;9(1):345
28. DilY, Strachan D, Cairncross S, Korkor AS, Hill Z. Motivations and challenges of community-based surveillance volunteers in the northern region of Ghana. J Community Health. 2012;37(6):1192-8.

29. Aswathy S, Beteena K, Leelamoni K. Mass drug administration against filariasis in India: perceptions and practices in a rural community in Kerala. Ann Trop Med Parasitol. 2009;103(7):617-24

30. Kisoka WJ, Tersbøl BP, Meyrowitsch DW, Simonsen PE, Mushi DL, et al. Community members' perceptions of mass drug administration for control of lymphatic filariasis in rural and urban Tanzania. J Biosoc Sci. 2016;48(1):94-112.

31. Gyapong JO, Owusu IO, Vroom FB, Mensah EO, Gyapong M. Elimination of lymphatic filariasis: current perspectives on mass drug administration. Res Rep Trop Med. 2018;9:25.

32. Krentel A, Gyapong M, Mallya S, Boadu NY, Amuyunzu-Namongo $M$, Stephens $M$, et al. Review of the factors influencing the motivation of community drug distributors towards the control and elimination of neglected tropical diseases (NTDs). PLoS Negl Trop Dis. 2017; 11(12):e0006065.

33. Adams AM, Vuckovic M, Birch E, Brant TA, Bialek S, Yoon D, et al. Eliminating neglected tropical diseases in urban areas: a review of challenges, strategies and research directions for successful mass drug administration. Trop Med Infect Dis. 2018;3(4):122.

34. Kalyango JN, Rutebemberwa E, Alfven T, Ssali S, Peterson S, Karamagi C. Performance of community health workers under integrated community case management of childhood illnesses in eastern Uganda. Malar J. 2012;11:282.

35. Kolaczinski JH, Robinson E, Finn TP. The cost of antibiotic mass drug administration for trachoma control in a remote area of South Sudan. PLoS NTD. 2011;5(10):e1362.

\section{Publisher's Note}

Springer Nature remains neutral with regard to jurisdictional claims in published maps and institutional affiliations.

Ready to submit your research? Choose BMC and benefit from:

- fast, convenient online submission

- thorough peer review by experienced researchers in your field

- rapid publication on acceptance

- support for research data, including large and complex data types

- gold Open Access which fosters wider collaboration and increased citations

- maximum visibility for your research: over $100 \mathrm{M}$ website views per year

At BMC, research is always in progress.

Learn more biomedcentral.com/submissions 